Sokoto Journal of Medical Laboratory Science 2021; 6(4): 116 - 126

SJMLS - 6(4) - 012

\title{
Assessment of Haematological Parameters and Iron Profile of Commercial Cyclists in Ekiti State, Nigeria
}

OlayanjuA.O. ${ }^{1}$, Ikuwagu C.F. ${ }^{1}$, Adesina O. ${ }^{2}$, Fakoya, O.O. ${ }^{2}$, Enitan S. S.* ${ }^{2}$

Department of Medical Laboratory Science, College of Medicine and Health Science, Afe Babalola University, PMB 5454, Ado Ekiti, Nigeria ${ }^{1}$, Department of Medical Laboratory Science, School of Public and Allied Health, Babcock University, Ilishan Remo, Ogun State. Nigeria ${ }^{2}$.

Author for Correspondence*: +234-806-548-3761/enitans@babcock.edu.ng.ORCID Number: 00000001-5993-7920.https://dx.doi.org/10.4314/sokjmls.v6i4.12.

\section{Abstract}

Iron deficiency is one of the common nutritional deficiencies worldwide. The nature of work and lifestyle of commercial cyclists predisposes them to various conditions that can lead to anaemia, which in turn affect haematopoiesis and cause morbidity and mortality. The aim of this cross-sectional study was to determine and compare haematological parameters and iron profile of commercial cyclists and apparently healthy individuals in Ekiti State, Nigeria and to further investigate degree of correlation. between serum iron (SI) levels, ferritin, and total iron binding capacity to the haematological parameters of Ekiti state commercial cyclists and apparently healthy individuals. Sequestrated blood samples $(5 \mathrm{ml})$ were obtained after administration of a structured questionnaire. The results obtained were analysed using SPSS version 21. Independent t-test and ANOVA were used to compare the means of the group studied. Pearson's correlation was used to determine relationship between the variables. Decreased values were observed in the haematological parameters, serum iron, and ferritin of commercial cyclists when compared to controls. Commercial cyclists showed a significantly lower $(p>0.05)$ in PCV $(p=0.0423)$, HGB $(p=0.0319), \operatorname{MCHC}(p=0.0445), \operatorname{PLT}\left(\times 10^{6} / \mathrm{L}\right)$ $(p=0.001), \operatorname{MPV}(p=0.0469), S I(p=0.0342)$, and ferritin $(p=-0.0026)$. Ferritin showed a weak positive correlation with PCV $(\mathrm{r}=0.35)$, $\operatorname{HGB}(\mathrm{r}=0.35), \operatorname{MCV}(\mathrm{r}=0.03), \mathrm{MCH}(\mathrm{r}=0.21)$, MCHC (0.10), RBC ( $\mathrm{r}=0.18)$. The pattern of results differed slightly in other parameters like WBC $(r=0.08)$, PLT $(r=-0.15)$, PCT $(-0.17)$, MPV ( $\mathrm{r}=0.09)$, PDW-SD ( $\mathrm{r}=-0.02)$ and PDW-
CV ( $\mathrm{r}=-0.11)$. There is a correlational relationship between ferritin and haematological parameters in Ekiti state commercial cyclists and this may affect their performance including vision and cognitive balance which can result in increased risk of road accidents.

Key Words: Commercial Cyclists, Ekiti State, Haematological Parameters, Iron profile, Nigeria

\section{Introduction}

In Nigeria, the use of commercial cycling (Okada riding) as a means of transportation has been in existence for a long time which started around the late 1980s. Over the years, this means of transportation has become accepted and the most popular informal means of transportation (Abdussalam et al., 2014). Many factors may be attributed to the wide acceptance and increased penetration of Okada riding in Nigeria. Some of the factors include the rapid rate of urbanisation in the face of inadequate means of transportation, high rate of unemployment and the relative lucrative nature of the business (Ikeano and Akinrolabu, 1991).

Cycling, just like any other occupation has its own occupational hazard, and some of the hazards associated with this profession have the ability to cause health related issues which can cause morbidity and mortality in this group of individuals. Prolonged sitting and standing are common physical activities that comes with the occupation which can cause Haemorrhoids, also called piles or varicose veins of the anus and rectum. Haemorrhoids are masses or clumps or cushions of tissues consisting of muscle and 
elastic fibres with enlarged, bulging blood vessels and surrounding supporting tissues present in the anal canal of an individual suffering from the disease. It is associated with prolapsing of an anal cushion that may result in bleeding and pain (Kona, 2010). Cycling often worsens the condition due to pressure on the anal area from sitting on the bike over a long period of time (Valachi and Valachi, 2003). Haemorrhoids is accompanied by rectal bleeding, associated with bowel movement, itching and pain as common symptoms. When venous congestion increases in the area and acute blood thrombi forms, in a short period of time, one to four days being the peak, there is a rapid increase in volume and internal pressure. When there is no pain, patients often experience symptoms such as rectal swelling, a mass, or prolapsing (Yamana, 2017). Haemorrhoids cause gastrointestinal bleeding, which is an established cause of iron deficiency anaemia. Anaemia seen in patients with gastrointestinal bleeding, is usually normocytic normochromic due to decreased erythropoietin production and red blood cell survival (Toke, 2010).

Exposure and consequent inhalation of poisonous gas and fumes from bike exhaust is another occupational hazard common among cyclists. the bikes have no covering unlike cars which make cyclists prone to inhalation of fumes from exhaust of cars during traffic. Gas or petrol is a volatile liquid with a complex mixture of aliphatic and aromatic hydrocarbons. It is commonly used as fuel for internal combustion engines which is directly inhaled by commercial cyclists. Some of its constituents are known to be highly toxic or carcinogenic to humans (Mehlman, 1990). These components include benzene, toluene, ethylene and xylene, which are also known as volatile organic compound (Kirchstetter et al., 1999).

Occupational exposure to petroleum products and fumes has toxic effects on various organs and body systems with high impact on the human respiratory system. Organs such as the heart, lungs, skin and kidneys are also affected by these toxic substances resulting in various diseases and different forms of genotoxic, mutagenic, immunotoxic, carcinogenic and neurotoxic manifestation (Ross, 1996). Studies have shown that inhalation of petroleum products is associated with reduced haematological indices which worsens with prolonged exposure (Okoro et al., 2006).

Other than occupational hazard, the lifestyle patterns of commercial cyclists aimed at enhancing performance may have negative impact on their health. Driving or cycling under the influence of drugs that acts on the brain could impair one's motor skills, reaction time, judgment, perception, cognition, attention, balance, coordination and other faculties required for safe driving. These commercial cyclists abuse certain substances to enhance performance; to remain alert throughout the day (cigarettes, cannabis), as a way to relax (alcohol) and to reduce pain (aspirin) (Etim and Ottu, 2010). Alcohol and other substance abuse have been identified as major causes of motorcyclists' crash in past studies in and outside Nigeria. Some studies in Nigeria have attributed fatal road traffic accidents to excessive intake of alcohol. reasons for the use of alcohol among Okada riders may include being alert while working, suppress fatigue, peer pressure, and mood elevation. Another reason for easy patronage of alcohol among cyclists in Nigeria is because alcohol retailers run their businesses close to most Okada parks hence an easy access to alcohol. Alcohol and substance abuse is known to impair a rider's sense of judgement and leads to excessive speeding and violent riding. Alcohol and substance abuse has adverse effects on the blood or haematopoietic, system, which can be direct or indirect. Chronic excessive alcohol ingestion reduces the number of blood cell precursors in the bone marrow and causes characteristic structural abnormalities in these cells, resulting in fewer-than-normal or nonfunctional mature blood cells. As a result, alcoholics may suffer from moderate anaemia, characterized by enlarged, structurally abnormal RBC's; mildly reduced numbers of (White blood cells) WBC's, especially of neutrophils; and moderately to severely reduced numbers of platelets (Ballard, 1993). Alcohol and substance abuse interferes with the normal production and function of WBC's, macrophages and monocytes which form the body's defense against 
microorganisms and other foreign substances. Neutropenia is common which may be associated with poor neutrophil development in the bone marrow which affects neutrophil delivery to infected sites (Harold, 1997). On the blood clotting system Alcohol and substance abuse can interfere with coagulation processes at several levels, causing, abnormally low platelet numbers in the blood (thrombocytopenia), impaired platelet function (i.e., thrombocytopathy), and diminished fibrinolysis (Lindenbaum and Hargrove, 1968).

Iron has various vital functions in the body. It serves as a carrier of oxygen to the tissues from the lungs by red blood cell haemoglobin, as a transport medium for electrons within cells, and as an integrated part of important enzyme systems in various tissues (Hurrell, 1997). The use of alcohol and drugs can lead to either iron deficiency or iron overload. In many alcoholics and substance abusers, blood loss and subsequent iron deficiency are caused by gastrointestinal bleeding. Iron deficiency in these individuals is often difficult to diagnose, because it may be masked by symptoms of other nutritional deficiencies (e.g., folic acid deficiency) or by coexisting liver disease and other alcohol-related inflammatory conditions.

Alcohol abuse can also increase iron levels in the body. For example, iron absorption from the food in the gastrointestinal tract may be elevated in alcoholics. Iron levels also can rise from excessive ingestion of iron-containing alcoholic beverages, such as red wine. The increased iron levels can cause haemochromatosis, a condition characterized by the formation of iron deposits throughout the body (e.g., in the liver, pancreas, heart, joints, and gonads).

Iron deficiency or overload will affect the haematological indices of cyclists which can affect their general health and have adverse effects on their performance thereby increasing risk for road accidents in the metropolis and this is fast emerging as in important public health issue.

\section{Materials and Methods Research Design}

This is a cross- sectional study involving commercial cyclists of the public in Ado-Ekiti, Ekiti State and apparently healthy (asymptomatic) and symptomatic subjects. The commercial cyclists recruited included those who are alcoholics, non-alcoholics, substance abusers and non- substance abusers. All relevant information including their sociodemographic characteristics, age, occupation, history of ailments, habits (past and present drinking, smoking, eating habits) were analysed using tables, and percentages.

\section{Sample Collection}

Five millimetres $(5 \mathrm{ml})$ of venous blood was collected from the ante-cubital fossa of each participant using disposable needles and syringes. One millimetre was dispensed into ethylene diamine tetra acetic acid (EDTA k3) bottle and the other $4 \mathrm{ml}$ into a plain bottle. The samples in the plain bottles were centrifuged for 10 minutes at $4000 \mathrm{rpm}$ and separated into plain bottles for ferritin, serum iron, total iron -binding capacity while the samples in the EDTA bottles were analysed for haematological parameters. The Full Blood parameters were analysed with Mindray BC-5000 (Mindray, China).

\section{Estimation of Serum Iron \\ Principle of The Assay}

Iron is dissociated from the transferrin-iron complex in weakly acid medium. Liberated iron is reduced into the bivalent form by means of ascorbic acid. Ferrous ions with Nitro-PAPS (2-5-nitro-2-pyridylazo)-5-(n-propyl-n-(3-sulfopropyl-amino-phenol) give a coloured complex:

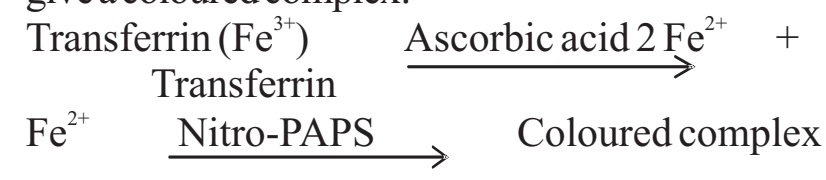

The intensity of the coloured complex formed is proportional to the iron concentration in the sample.

\section{Procedure}

1. Into the cuvette labelled for reagent blank, 100ul of Reagent 1(iron free water) was dispensed.

2. $1000 \mathrm{ul}(1 \mathrm{ml})$ of buffer $\mathrm{R} 1$ was dispensed into both reagent blank cuvette, standard cuvette and sample cuvette.

3. 100ul of standard and 100ul of sample was dispensed into the cuvettes labelled standard 
and sample respectively. It was mixed and the initial absorbance A1 of the sample and the standard was read against the reagent blank.

4. Then 250ul of Reagent 2 (chromogen) was added into all cuvettes. It was mixed and the absorbance A2 was read after 5 minutes of incubation at room temperature $\left(18^{\circ} \mathrm{C}-25^{\circ} \mathrm{C}\right)$.

\section{Procedure for Ferritin \\ Principle of The Assay}

The Ferritin Quantitative Test Kit is based on a solid phase enzyme-linked immunosorbent assay. The assay system utilizes one anti-ferritin antibody for solid phase (microtiter wells) immobilization and another mouse monoclonal anti-ferritin antibody in the antibody-enzyme (horseradish peroxidase) conjugate solution. The test sample is allowed to react simultaneously with the antibodies, resulting in the ferritin molecules being sandwiched between the solid phase and enzyme-linked antibodies. After a 60minute incubation at room temperature, the wells are washed with water to remove unbound labelled antibodies. A solution of TMB is added and incubated for 20 minutes, resulting in the development of a blue colour. The colour development is stopped with the addition of $2 \mathrm{~N}$ HCL, and the colour is changed to yellow and measured spectrophotometrically at $450 \mathrm{~nm}$. The concentration of ferritin is directly proportional to the colour intensity of the test sample.

1. The desired number of coated wells was placed in the holder.

2. 20ul of standards, controls and samples was pipetted into the appropriate wells and 100ul of Enzyme Conjugate Reagent was pipetted into each well.

3. The plate was rocked for $10-30$ seconds. The plate was covered and incubated at room temperature $\left(18-25^{\circ} \mathrm{C}\right)$ for 60 minutes.

4. The liquids from the wells were removed by flicking the paper content into a waste container. The microtiter well was rinsed five times with running tap or distilled water. Then the well was blotted on to absorbent paper or paper towels to remove all residual water droplets. 200ul of TMB solution was dispensed into each well. It was gently mixed for 5 seconds. It was incubated at room temperature in the dark for 20 minutes. The reaction as stopped by adding $50 \mathrm{ul}$ of $2 \mathrm{~N}$ HCL to each well.

5. It was gently mixed for 30 seconds. Optical density was read at $450 \mathrm{~nm}$ with a microtiter reader within 30 minutes.

\section{Estimation of Total Iron Binding Capacity Principle of The Test}

The serum is treated with excess $\mathrm{Fe}_{2}$ to saturate the iron binding sites on transferrin. This excess $\mathrm{Fe}_{2}$ is adsorbed and precipitated and the iron content in the supernatant is measured to give TIBC.

$\mathrm{Fe}_{(3)} \quad$ Acid Medium $\longrightarrow \mathrm{Fe}_{(2)}$ $\mathrm{Fe}_{(2)}+$ Ferrozine $\longrightarrow$ Violet Coloured Complex

\section{Procedure}

1. Into a clean dry test tube $0.5 \mathrm{ml}$ of serum was dispensed.

2. To the serum $1 \mathrm{ml}$ of TIBC reagent was added and mixed carefully. The tubes were allowed to stand for 10 minutes at room temperature and a clear supernatant was obtained by centrifuging at 2500-3000 rpm for 10 minutes.

3. The iron content was determined colorimetrically at $570 \mathrm{~nm}$.

\section{Data Analysis}

Statistical analysis was performed using the Statistical Package for Social Sciences (SPSS) software version 21.0. Numerical data were expressed as mean \pm standard deviation (SD) for study participants and controls. Independent Ttest and Analysis of Variance (ANOVA) was used to compare the difference between the means of the two groups studied. Pearson's correlation was used to investigate the relationship between the biochemical parameters (ferritin, serum iron, Total iron binding capacity and red cell indices) and haematological parameters studied. The level of statistical significance was set at a $P$-value less than 0.05 .

\section{Results}

The present study assessed the haematological correlates of iron profile and haematological parameters of Ekiti commercial cyclists. The 
sociodemographic characteristics of the study participants is presented in Table 1 . The dietary consumption and substance abuse in commercial cyclists is shown in Table 2. Table 3 shows the knowledge of haemorrhoids among commercial cyclists. Table 4 showed the mean and standard deviation of the haematological parameters and iron parameters of the study participants and control. Table 5 shows the statistical difference ( $p$-value) of the haematological parameters and iron profile in test and control. Table 6 shows Ferritin correlation with haematological parameters in study participants.

Table 1: Sociodemographic Characteristics of Commercial Motorcyclist

\begin{tabular}{|c|c|c|}
\hline \multirow[t]{2}{*}{ Gender } & Male & 97.1 \\
\hline & Female & 2.9 \\
\hline \multirow[t]{4}{*}{ Age } & 20-30yrs & 35.3 \\
\hline & $31-40 y r s$ & 43.1 \\
\hline & $41-50 y r s$ & 19.6 \\
\hline & 51 and above & 2 \\
\hline \multirow[t]{3}{*}{ Ethnicity } & Igbo & 2.9 \\
\hline & Yoruba & 77.5 \\
\hline & Hausa & 9.8 \\
\hline \multirow[t]{4}{*}{ Religion } & Christianity & 78.4 \\
\hline & Islam & 20.6 \\
\hline & Others & 1 \\
\hline & Formal & 68.6 \\
\hline \multirow[t]{2}{*}{ Education Level } & education & \\
\hline & $\begin{array}{l}\text { No formal } \\
\text { education }\end{array}$ & 9.8 \\
\hline \multicolumn{3}{|l|}{ Years of being a commercial } \\
\hline \multirow[t]{4}{*}{ cyclist } & $1-5 y r s$ & 18.6 \\
\hline & 6-10yrs & 23.5 \\
\hline & $10-15$ yrs & 29.4 \\
\hline & $15 y r s$ and above & 23.5 \\
\hline \multirow[t]{2}{*}{ Full time/Part time } & Full time & 58.8 \\
\hline & Part time & 36.3 \\
\hline \multirow[t]{4}{*}{ Time spent riding per day } & 1-5hrs & 28.4 \\
\hline & 6-10hrs & 40.2 \\
\hline & $11-16 h r s$ & 14.7 \\
\hline & 17 hrs and above & 10.8 \\
\hline \multirow[t]{6}{*}{ Duration of break per day } & 10-30min & 11.8 \\
\hline & $30 \mathrm{~min}-1 \mathrm{hr}$ & 30.4 \\
\hline & $2 \mathrm{hrs}$ & 22.5 \\
\hline & 3hrs & 15.7 \\
\hline & 3 hrs and above & 6.9 \\
\hline & None & 6.9 \\
\hline
\end{tabular}


Table 2: Dietary and substance abuse status

\begin{tabular}{|c|c|c|}
\hline \multirow[t]{4}{*}{ Frequency of eating } & Once a day & 2 \\
\hline & 2 times a day & 13.7 \\
\hline & 3 times a day & 52 \\
\hline & Anytime & 32.4 \\
\hline \multirow[t]{4}{*}{ Class of food majorly eaten } & Carbohydrate & 79.4 \\
\hline & Protein & 10.8 \\
\hline & Fat and oil & 1 \\
\hline & Others & 5.9 \\
\hline \multirow[t]{4}{*}{ Intake of balanced diet } & Yes & 29.4 \\
\hline & No & 35.3 \\
\hline & Sometimes & 33.3 \\
\hline & Not at all & 1 \\
\hline \multirow[t]{2}{*}{ Alcohol intake } & Yes & 55.9 \\
\hline & No & 43.1 \\
\hline \multirow[t]{3}{*}{ Purpose of alcohol intake } & Pleasure & 43.1 \\
\hline & $\begin{array}{l}\text { To supress } \\
\text { weakness }\end{array}$ & 8.8 \\
\hline & Others & 3.9 \\
\hline \multirow[t]{2}{*}{ Take alcohol before riding } & Yes & 14.7 \\
\hline & No & 62.7 \\
\hline \multirow[t]{2}{*}{ Cigarrete intake } & Yes & 14.7 \\
\hline & No & 69.6 \\
\hline \multirow[t]{2}{*}{ Use of cigarrete before riding } & Yes & 5.9 \\
\hline & No & 69.6 \\
\hline \multirow[t]{2}{*}{ Drug intake } & Yes & 22.5 \\
\hline & No & 53.9 \\
\hline \multirow[t]{5}{*}{ Kind of drug taken } & Tramadol & 5.9 \\
\hline & Codeine & 1 \\
\hline & Indian hemp & 7.8 \\
\hline & Reffinol & \\
\hline & Others & 2 \\
\hline \multirow[t]{4}{*}{ Purpose of drug intake } & Pleasure & 9.8 \\
\hline & $\begin{array}{l}\text { To suppress } \\
\text { fatigue }\end{array}$ & 1 \\
\hline & To keep awake & \\
\hline & Others & 2 \\
\hline
\end{tabular}


Table 3: General knowledge on table haemorrhoids

\begin{tabular}{llc}
\hline Question & Responses & Percent (\%) \\
\hline Previous knowledge about & Yes & 83.3 \\
haemorrhoids & No & 13.7 \\
Ever been affected by & Yes & 66.7 \\
haemorrhoids & No & 23.5 \\
& Less than a year & 12.7 \\
& One year & 6.9 \\
Duration of been affected & 2yrs & 3.9 \\
& 3yrs & 2 \\
& & 34.3 \\
& 4yrs \& above & 53.9 \\
Symptoms experienced & Pains & 2 \\
& Anal swelling & 3.9 \\
\hline
\end{tabular}

Table 4: Mean \pm STD of commercial cyclists (test) and apparently healthy males within the same age group (control)

\begin{tabular}{lll}
\hline Parameter & Test & Control \\
\hline *PCV (\%) & $43.1 \pm 3.61$ & $46.2 \pm 2.8$ \\
*HGB (g/dl) & $14.4 \pm 1.23$ & $15.5 \pm 1.13$ \\
MCV (fl) & $87 \pm 7$ & $88 \pm 4.7$ \\
MCH (pg) & $29 \pm 3$ & $32 \pm 3$ \\
*MCHC (\%) & $32 \pm 1$ & $37 \pm 4$ \\
RBC (10 $\left.{ }^{12} / \mathrm{L}\right)$ & $4.816 \pm 0.577$ & $4.95 \pm 0.75$ \\
*RDW-SD (fl) & $47 \pm 4$ & $44 \pm 2.4$ \\
RDW-CV (\%) & $14.96 \pm 1.238$ & $14.7 \pm 1.1$ \\
WBC (10/L) & $5.181 \pm 2.05$ & $6.8 \pm 2.4$ \\
*PLT (10\%/L) & $169.4 \pm 48.26$ & $217 \pm 12$ \\
*PCT (\%) & $0.14 \pm 0.05$ & $0.18 \pm 0,03$ \\
*MPV (fl) & $8.21 \pm 1.3$ & $9.8 \pm 0.9$ \\
PDW-SD (fl) & $20.322 \pm 2.741$ & $212.27 \pm 1.6$ \\
PDW-CV (\%) & $37.49 \pm 1.276$ & $38.3 \pm 1.37$ \\
*SI (umol/L) & $178 \pm 31$ & $218 \pm 26$ \\
TIBC ((ug/dl) & $411 \pm 38$ & $314 \pm 27$ \\
*Ferritin (ug/L) & $74.8958 \pm 6.69$ & $112 \pm 17$ \\
\hline
\end{tabular}

*considered statiscally significant 
Table 5: Mean \pm STD, (P-Value) of Haematological Parameters and Iron Profile Between Commercial Cyclists (Test) and Apparently Healthy Males Within the Same Age Group (Control)

\begin{tabular}{lllc}
\hline Parameter & Test & Control & P-Value \\
\hline *PCV (\%) & $43.1 \pm 3.61$ & $46.2 \pm 2.8$ & 0.0423 \\
*HGB (g/dl) & $14.4 \pm 1.23$ & $15.5 \pm 1.13$ & 0.0319 \\
MCV (fl) & $87 \pm 7$ & $88 \pm 4.7$ & 0.06832 \\
MCH (pg) & $29 \pm 3$ & $32 \pm 3$ & 0.0822 \\
*MCHC (\%) & $32 \pm 1$ & $37 \pm 4$ & 0.0445 \\
RBC (10 $12 / \mathrm{L})$ & $4.816 \pm 0.577$ & $4.95 \pm 0.75$ & 0.5391 \\
*RDW-SD (fl) & $47 \pm 4$ & $44 \pm 2.4$ & 0.0394 \\
RDW-CV & $14.96 \pm 1.238$ & $14.7 \pm 1.1$ & 0.1293 \\
WBC (10 $/ \mathrm{L})$ & $5.181 \pm 2.05$ & $6.8 \pm 2.4$ & 0.8492 \\
*PLT (10 $/ \mathrm{L})$ & $169.4 \pm 48.26$ & $217 \pm 12$ & 0.0001 \\
*PCT (\%) & $0.14 \pm 0.05$ & $0.18 \pm 0,03$ & 0.0023 \\
MPV (fl) & $8.21 \pm 1.3$ & $9.8 \pm 0.9$ & 0.0469 \\
PDW-SD (fl) & $20.322 \pm 2.741$ & $212.27 \pm 1.6$ & 0.6383 \\
PDW-CV (\%) & $37.49 \pm 1.276$ & $38.3 \pm 1.37$ & 0.3342 \\
*SI (umol/L) & $178 \pm 31$ & $218 \pm 26$ & 0.0342 \\
TIBC (ug/dl) & $411 \pm 38$ & $314 \pm 27$ & 0.4733 \\
*Ferritin (ug/L) & $74.8958 \pm 6.69$ & $112 \pm 17$ & 0.0026 \\
\hline
\end{tabular}

*considered statistically significant.

Table 6: Correlation between ferritin and haematological parameters

\begin{tabular}{ll}
\hline & Ferritin \\
\hline PCV (\%) & $r=0.35$ \\
HGB (g/d1) & $r=0.35$ \\
MCV (fl) & $r=-0.03$ \\
MCH (pg) & $r=0.21$ \\
MCHC (\%) & $r=0.1$ \\
RBC (10 $12 / \mathrm{L})$ & $r=0.18$ \\
RDW-SD (f1) & $r=0.07$ \\
RDW-CV (\%) & $r=0.13$ \\
WBC (10 /L) & $r=-0.08$ \\
PLT (10 $/ \mathrm{L})$ & $r=-0.15$ \\
PCT (\%) & $r=-0.17$ \\
MPV (f1) & $r=-0.09$ \\
PDW-SD (f1) & $r=-0.02$ \\
PDW-CV (\%) & $r=-0.11$ \\
\hline
\end{tabular}




\section{Discussion}

Haemoglobin was significantly lower $(\mathrm{p}<0.05)$ decrease was observed in the mean values of test when compared to controls. This observation is similar to a study carried out in Owerri, Nigeria on the effect of chronic Alcohol consumption on haematological and Cardio hepatic function markers among commercial motorcyclists, showing that $\mathrm{Hb}$ was lower in test compared to controls. This result may be due to the consumption of alcohol, as alcohol supresses appetite which can interfere with nutrient availability and utilization by the body causing malnutrition (Igoh et al., 2009). The low haemoglobin value may be associated with the inhibitory factors of certain dietary foods, for instance, phyate present in cereals and grains that prevent iron absorption thereby affecting the formation of heme (Aggett, 2012).

Iron is an essential element for blood production, and necessary for the formation of haemoglobin responsible for the oxygen -carrying capacity of red blood cells (Hurrell, 2007). Serum iron levels in the tests were significantly lower $(p<0.05)$ when compared to controls. Ferritin, which is a storage form of iron and correlates accurately with iron body stores also showed significantly reduced values in commercial cyclists compared to apparently healthy individuals. This could be due to alcohol ingestion as its metabolism prevents the body from properly absorbing food nutrients (Lieber, 2003). This is in contrast to what is usually seen in professional road cyclists who usually have high ferritin levels. Professional road cyclists are known to use excessive iron supplementation to enhance performance (Kalantar-Zadeh et al., 2005; Zottter etal., 2004).

However, in the case of TIBC in this study, test values were higher than control values although not significant. $(p>0.05)$ This could be as a result of an increased unsaturated iron binding capacity due to the transferrin receptors not being able to bind as much ferrous ion (Fe II) in order for transport to be used for storage and sequestration of haemoglobin (Bruer et al., 2000).

A weak positive correlation was observed between ferritin and mean cell haemoglobin
$(\mathrm{MCH})$ with mean values of test lower than controls. The differences in $\mathrm{MCH}$ can be said to be associated to a decrease in haemoglobin content of the blood which has a close relationship with iron levels which is influenced by dietary habits (Igoh et al., 2009).

In this study, it was observed that total white blood cell (WBC) count had a weak negative correlation with ferritin. Mean values obtained from test were lower compared to controls although not significant ( $p>0.05)$. This agrees with the finding in a previous report (Igoh et al., 2009) which had lesser values of WBC in test compared to control.

There was a significant $(p<0.05)$ decrease of Platelet values in test when compared to controls which this reduced count could be because heavy drinking may induce thrombocytopenia and a weak negative correlation with ferritin.

$\mathrm{RBC}$ had mean levels of the test lower when compared to controls which was not significant $(p>0.05)$ and a weak positive correlation with ferritin. This is also consistent with previous study from Igboh et al. (2009). PCV as an index of anaemia was observed to be significantly $(p<$ 0.05 ) lower when compared with control and a weak positive correlation with ferritin.

This study showed general haematological parameters to be lower in commercial cyclists compared to apparently healthy males within the same age group. Serum iron and serum ferritin were also decreased in commercial cyclists. This decrease can be attributed to malnutrition and behavioural factors common amongst commercial cyclists like alcoholism and substance abuse that affect iron absorption and blood indices. TIBC was higher in commercial cyclists when compared to apparently healthy males within the same age group.

\section{Conclusion}

Iron status and haematological parameters were lower in commercial cyclists when compared to apparently healthy controls with exception to TIBC which was observed to be higher in test subjects. The observed values correlated in varying degrees with the iron parameters. 
Therefore, it can be said that an association exists between serum iron, storage form of iron, ferritin levels with haematological parameters of commercial cyclists in Ekiti. This has implications on the general health of the cyclist and may affect performance including visual disturbances which may result in increased incidence of accidents in the metropolis.

\section{Disclosure of conflict of interest}

All authors declare no form of conflict of interest in this study.

\section{Funding}

This research work was self-sponsored. No funding was received from any funding agency.

\section{Authors' contributions}

This work was carried out in collaboration among all authors. Authors OAO and ICF designed the study, wrote the protocol and the first draft of the manuscript. Authors ICF and AO managed the analyses of the study. Authors FOO and ESS managed the literature searches. Author ICF performed the statistical analysis. All authors read and approved the final manuscript.

\section{References}

Abdussalam, Onagun I., Adio S. Wahab (2014). Is "Okada" Commercial Motorcycle Riding Reducing Poverty Among Operators in Ilorin West Local Government Area, Kwara State? European Journal of Business, Economics and Accountancy; 2(3): 2056-6018.

Aggett P.J. (2012). Iron. In: Erdman J. W., Macdonald L. A., Zeisel S. H. eds. Present knowledge in Nutrition. $10^{\text {th }}$ ed Washington, DC: Wiley-Blackwell: 506-520.

Ballard, H. S. (1993). Alcohol, bone marrow, and blood. Alcohol Health \& Research World; 17(4):310-315.

Bruer, W., Ronson A., Slotki I.N., Abramov A., Hershko C. and Cabantchick, Z.I. (2000). The assessment of serum non-transferrinbound iron in chelation therapy and iron supplementation. Blood; 95:2975-2982.

Etim, S.I. and Ottu, I. (2010). Psychological correlates of substance abuse in nonpsychiatric and psychiatric populations. Nigerian Journal of Psychiatry;2(2): 8-13.

Harold, S. (1997). The Haematological
Complications of Alcoholism. Alcohol Health and Research World; 21(1): 42-51.

Hurrell, R.F. (1997). Bioavailability of iron. European Journal of Clinical Nutrition; 51: S4-8.

Igoh N.M., Agomuo E.N., Onwubiko D., Onyesom I., Maduagwuna C.A. and Uzuegbu U.E. (2009). Effect of Chronic Alcohol Consumption and Cardiohepatic Function Markers Among Commercial Motor Cyclists in Owerri, Nigeria. Biomedical and Pharmacology Journal; 2(1): 596.

Ikeano N. and Akinrolabu, F. (1991). "Transportation: Commuters tell Story of Woes". Iwamoto T, DeVoe G. (1976). Electron microscopic study of the Fleischer Ring. Archives of Ophthalmology; 94: 1579-1583.

Kalantar-Zadeh K., Hoffken B., Wunsech H., Fink H., Kleiner M. and Luft, F.C. (1995). Diagnosis of iron deficiency anaemia in renal failure patients during the post-erythropoetin era. American Journal of Kidney Disease; 26(2): 292-299.

Kirchstetter T.W., Singer B.C., Harley R.A., Kendall, G.R. and Hesson J.M. (1999). Impact of California reformulated gasoline on motor vehicle emissions. 2. Volatile organic compound speciation and reactivity. Environmental Science and Technology; 33(2): 329-336.

Kona, V. (2010). Conditions and diseases of digestive system. available at: http/: www.OmniMedicalsearch.com, retrieved on January 16 2020. World Journal of Preventive Medicine;4(1): 1-3.

Lieber, C.S. (2003). Relationship between nutrition, alcohol use and liver disease. Alcohol Research and Health; 27:220-231.

Lindenbaum, J. and Hargrove, R.I. (1968). Thrombocytopenia in alcoholics. Annals of Internal Medicine; 68:526-532.

Mehlman M.A. (1990). Dangerous properties of petroleum-refining products: carcinogenicity of motor fuels (gasoline). Teratog Carcinog Mutagen;10(5): 399-408.

Okoro A.M., Ani, E.J., Ibu J.O. and Akpogomeh, B.A. (2006). Effect of Petroleum Products Inhalation on some Haematological Indices of Fuel Attendants in Calabar Metropolis, 
Nigeria. Nigerian Journal of Physiological Sciences; 21(1-2): 71-75.

Ross D. (1996). Metabolic Basis of Benzene Toxicity (Review). European Journal of Haematology;60: 111-118.

Toke, A.B. (2010). GI bleeding risk in patients undergoing dialysis. Gastrointestinal Endoscopy; 71(1): 50-52.

Valachi B. and Valachi K. (2003). Preventing musculoskeletal disorders in clinical dentistry: Strategies to address the mechanisms leading to musculoskeletal disorders. Journal of the American Dental
Association;134(12): 1604-1612.

Yamana, T. (2017). Japanese Practice Guidelines for Anal Disorders I. Hemorrhoids Journal of the Anus, Rectum and Colon; 1(3): 89-99.

Zottter, H., Robinson N., Zorzoli M., Schatterberg L., Saugy M., Mangin P. (2004). Abnormally high serum ferritin levels among professional road cyclists. British Journal of Sport Medicine; 38:704708.

Olayanju A.O., Ikuwagu C.F., Adesina O., Fakoya, O.O., Enitan S. S.

Citation: Olayanju A.O., Ikuwagu C.F., Adesina O., Fakoya, O.O., Enitan S. S. Assessment of Haematological Parameters and Iron Profile of Commercial Cyclists in Ekiti State, Nigeria. Sokoto Journal of Medical Laboratory Science; 6(4): 116 - 126.

Copyright. This is an open-access article distributed under the terms of the Creative Commons Attribution License, which permits unrestricted use, distribution, and reproduction in any medium, provided the original author and source are credited. 